\title{
The effect of low flow anesthesia on hemodynamic and peripheral oxygenation parameters in obesity surgery
}

\author{
Mesut Öterkuş, MD, İlksen Dönmez, MD, Aysu H. Nadir, MD, \\ İbrabim Rencüzoğulları, $M D$, Yavuz Karabă̆, MD, Kenan Binnetoğlu, $M D$.
}

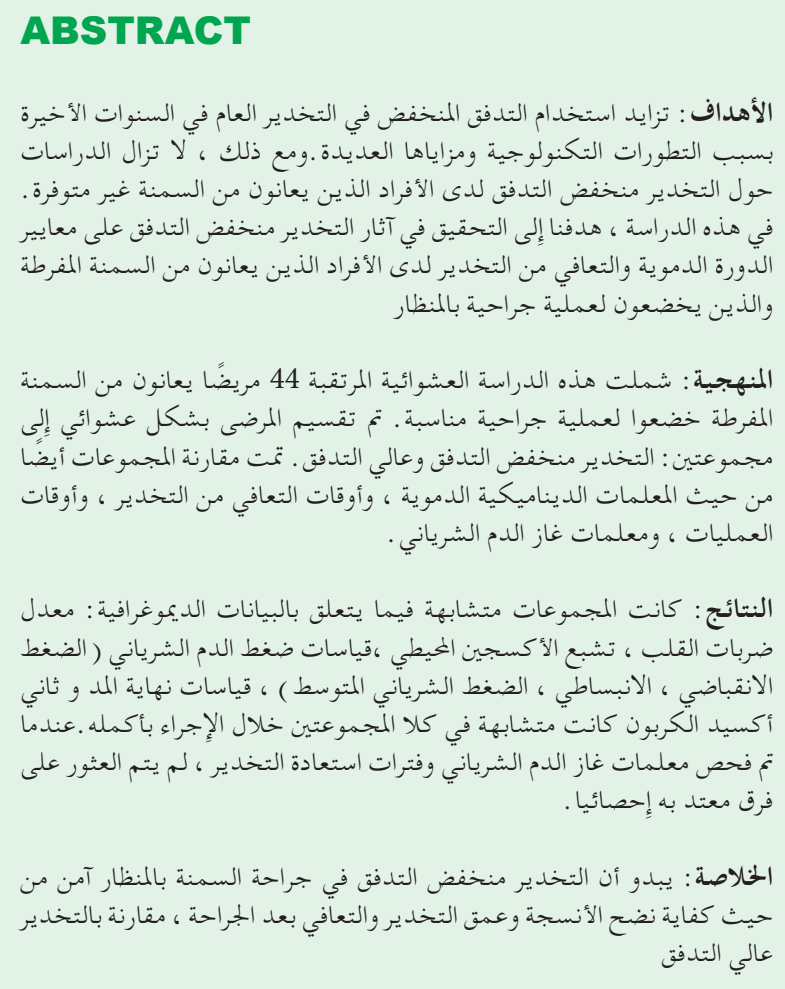

Objectives: To investigate the effects of low-flow anesthesia on hemodynamic parameters and recovery from anesthesia in obese individuals undergoing laparoscopic surgery.

Methods: This randomized-controlled and prospective study included 44 obese patients who underwent laparoscopic sleeve gastrectomy operation. The patients were randomly allocated into 2 groups as low-flow and high-flow anesthesia. Further, the groups compared in terms of hemodynamic parameters, anesthesia recovery times, operation times, and arterial blood gas parameters.

Results: The groups were similar with respect to demographic data. Heart rate, peripheral oxygen saturation, arterial blood pressure measurements, endtidal, and $\mathrm{CO}_{2}$, lactate levels measurements were similar in both groups during the entire procedure. There was also no statistically significant difference in terms of arterial blood gas parameters or anesthesia recovery periods.

Conclusion: Low-flow anesthesia in laparoscopic obesity surgery seems to be safer compared to high-flow anesthesia in terms of the adequacy of tissue perfusion, depth of anesthesia, and postoperative recovery.

Keywords: low-flow anesthesia, morbid obesity, bariatric/ metabolic surgery

Saudi Med J 2021; Vol. 42 (3): 264-269

doi: 10.15537/smj.2021.42.3.20200575

From the Department of Anesthesiology and Reanimation (Öterkuş), Faculty of Medicine, Malatya Turgut Özal University, Malatya; from the Department of Anesthesiology and Reanimation (Dönmez), Beyoglu Eye Training and Research Hospital, Istanbul; from the Department of Anesthesiology and Reanimation (Nadir), Izmir Katip Celebi University Ataturk Training and Research Hospital, İzmir; and from the Department of Cardiology (Rencüzoğullar, Karabă̆), Department of General Surgery (Binnetoğlu), Medical Faculty, Kafkas University, Kars, Turkey.

Received 7th October 2020. Accepted 24th January 2021.

Address correspondence and reprint request to: Dr. Mesut Öterkus, Assistant Professor, Department of Anesthesiology and Reanimation, Faculty of Medicine, Malatya Turgut Özal University, Malatya, Turkey. E-mail:mesutoterkus@hotmail.com

ORCID ID: http://orcid.org/0000-0003-1025-7662

$\mathrm{L}$ ow-flow anesthesia is a technique in which at least $50 \%$ of the exhaled gas is returned into the system by rebreathing. Although not preferred much in the past, this method has become widespread with the introduction of new generation anesthesia devices and monitors and volatile agents. Despite its prominent advantages such as reduction of environmental pollution, minimal loss of heat and moisture, and low cost due to the use of less anesthetic drugs, low-flow anesthesia needs a more advanced technical infrastructure due to the necessity to follow the patients more closely. ${ }^{1-3}$ Obesity surgery may lead to many complications, such as difficult intubation, 
increased risk of atelectasis, obesity hypoventilation syndrome, and so forth. ${ }^{4-6}$ In these patients, respiratory capacity, which is already constrained due to obesity, is further limited due to the presence of carbon dioxide $\left(\mathrm{CO}_{2}\right)$ insufflation and the lithotomy position during laparoscopic surgery. These factors increase the risk of developing hypoxia. Therefore, the use of low current was limited in these patients. However, considering the publications on tissue oxygenation for obese individuals with normal heart pumping functions and sufficient blood volume and hemoglobin levels, it can be predicted that oxygen will be sufficient at the tissue level in low-flow anesthesia. ${ }^{7}$ Also, there are studies where low-flow anesthesia in laparoscopic surgery resulted in successful outcomes in addition to balanced oxygen delivery consumption. ${ }^{8,9}$ Although limited, there are studies reporting use of low-flow anesthesia in bariatric surgery. ${ }^{9-11}$

This paper aims to examine the effects of low-flow anesthesia on arterial blood gas, hemodynamic parameters, and anesthesia recovery in patients with morbid obesity who underwent laparoscopic sleeve gastrectomy.

Methods. Concern for hypoxia plays an important role in avoiding the use of low flow in morbidly obese individuals. For this reason, studies on this subject remain limited. Therefore, we think that this original clinical study could be a reference to studies of low flow use in morbidly obese patients. The study proceeded with the permission from the Ethics Committee of the Clinical Research, Kafkas University, Kafkas, Turkey (26.06.2016/132). The ethical standards of the Declaration of Helsinki were adhered to. For the sample size of the study, a similar study previously conducted was referenced. The minimum sample size calculated by taking 0.05 alpha error and 0.20 beta error was found as 15 patients in both groups. This prospective randomized controlled clinical trial, which is also an equivalent clinical trial was performed with 44 adult patients with American Society of Anesthesiologists scores of I-II, aged $18-75$ years, and with a body mass index (BMI) of $>35 \mathrm{~kg} / \mathrm{m}^{2}$. Informed consent was obtained from all participants. Patients with cardiovascular disease, liver disease, pulmonary disease or cerebrovascular disease and those refusing to give an informed consent were

Disclosure. Authors have no conflict of interests, and the work was not supported or funded by any drug company. excluded. The references for the research were created using PubMed and Google academic indexes.

Upon receiving their informed consent, patients were randomly allocated to 2 groups as a study and a control group. This randomized study was performed by the blind anesthesiologist, who did not participate in the study, using the coin flip method. The patients were examined preoperatively and were taken to the operating room without premedication after the appropriate fasting period.

The leak test of the anesthesia device was performed for each patient before anesthesia. The soda lime used as the $\mathrm{CO}_{2}$ absorbent was changed when the color changed. Standard monitoring procedures were used for electrocardiogram, and peripheral oxygen saturation $\left(\mathrm{SpO}_{2}\right)$. Besides, a $20 \mathrm{G}$ cannula was inserted into the radial artery, and intraarterial pressure was continuously monitored. The patients underwent 5 minutes of preoxygenation $\left(100 \%\right.$ 4 $\left.\mathrm{L} / \mathrm{min} \quad \mathrm{O}_{2}\right)$ followed by propofol $2 \mathrm{mg} \mathrm{kg}^{-1}$ (Propofol 1\%, Fresenius ${ }^{\circledast}$ Fresenius Kabi Medicine, Istanbul, Turkey), fentanyl $1 \mathrm{mcg} \mathrm{kg}^{-1}$ (Fentanyl $0.05 \mathrm{mg} / \mathrm{ml}$, Johnson and Johnson Medicine, Istanbul, Turkey) and rocuronium bromide $0.6 \mathrm{mg} \mathrm{kg}^{-1}$ (Curon ${ }^{\circledast} 50$ mg/5 ml Mustafa Nevzat, Istanbul, Turkey) administered intravenously during the induction of anesthesia.

Following intubation with an appropriate endotracheal tube, patients were connected to the anesthesia device. End-tidal carbon dioxide $\left(\mathrm{EtCO}_{2}\right)$, amount of sevoflurane, nitrous oxide, and oxygen flow were continuously monitored after intubation.

In order to provide faster depth of anesthesia at the beginning of anesthesia in the low-flow (study) group, the combination of $2 \mathrm{~L} \mathrm{~min}^{-1}$ nitrous oxide $\left(\mathrm{N}_{2} \mathrm{O}\right), 2 \mathrm{~L} \mathrm{~min}^{-1}$ oxygen $\left(\mathrm{O}_{2}\right)$, and $2-3 \%$ sevoflurane (Sevorane $^{\oplus}$, Liquid $100 \%$, Queenborough, UK) was administered with a minimum alveolar concentration (MAC) of 1 for 5 minutes. Later, $50 \% \mathrm{O}_{2}+50 \% \mathrm{~N}_{2} \mathrm{O}$ and $2-3 \%$ sevoflurane was given by setting the fresh gas flow to $1 \mathrm{~L} \mathrm{~min}^{-1}$. In the high-flow (control) group, a combination of $2 \mathrm{~L} \mathrm{~min}^{-1} \mathrm{~N}_{2} \mathrm{O}, 2 \mathrm{~L} \mathrm{~min}^{-1} \mathrm{O}_{2}$, and $2-3 \%$ sevoflurane was given at the same concentration throughout the procedure. At the end of the operation, fresh gas flow was removed at 6-8 $\mathrm{L} \mathrm{min}^{-1}$ and inhalation of the anesthetic agent was closed for all patients. Ventilation was continued manually with $100 \% \mathrm{O}_{2}$. For the reversal of the neuromuscular block, neostigmine $0.04 \mathrm{mg} / \mathrm{kg}^{-1}$ (Neostigmine, Adeka Samsun, Turkey) and atropine $0.02 \mathrm{mg} / \mathrm{kg}^{-1}$ (Atropine Sulphate, Galen Medical, Istanbul, Turkey, $0.02 \mathrm{mg} \mathrm{kg}^{-1}$ intravenously) were administered. For the treatment of postoperative pain, tramadol $\left(1 \mathrm{mg} / \mathrm{kg}^{-1}\right)$ and dexketoprofen $(50 \mathrm{mg})$ were administered. 
Patients' demographic data, vital signs at $30 \mathrm{~min}$ intervals (heart rate [HR], peripheral oxygen saturation $\left[\mathrm{SpO}_{2}\right]$, and arterial pressure), and preoperative, intraoperative $(30,60,90$ and $120 \mathrm{~min})$, and postoperative arterial blood gas values, operation times, and postoperative complications were recorded. In this clinical trial, we do not analyze the variability of the vital signs according to the time in their own. We analyzed all vital signs between groups for each minutes as aforementioned.

Statistical analysis were performed using the Statistical Package for Social Sciences (IBM Corp., Armonk, NY, USA) version 22. Continuous and categorical variables are expressed as mean \pm standard deviation and percentages. Differences in subject characteristics between low-flow and high-flow anesthesia were analyzed using the t-test and the Mann-Whitney $\mathrm{U}$ test for continuous variables and the Chi-squared test/Fisher's exact test for categorical variables. The dependent t-test and repeated measurement analysis of variance (ANOVA) and the Friedman test were used to compare laboratory parameters between the beginning and the end of the study period.

Results. The study population consisted of 44 patients (mean age $36 \pm 9$ years; $31.8 \%$ male) who underwent sleeve gastrectomy operation. The low-flow anesthesia technique was performed in 27 (61.4\%) patients and the high-flow anesthesia technique was performed in 17 (38.6\%).

The 2 groups were statistically similar in terms of demographic data. Patients' demographic, clinical, and operation feature are listed in Table 1. Ten-minute HR values were statistically higher in the high-flow anesthesia group $(p=0.035)$. Heart rate values at other times were similar in both groups $(p>0.05)$. Systolic, diastolic, mean arterial pressures, end tidal $\mathrm{CO}_{2}$ levels, and $\mathrm{O}_{2}$ saturation were similar in both groups ( $p>0.05$ for all) (Table 2). Arterial blood gas values

Table 1 - Demographic data.

\begin{tabular}{lccc}
\hline Demographic data & $\begin{array}{c}\text { High-flow } \\
\mathbf{n}=\mathbf{1 7}\end{array}$ & $\begin{array}{c}\text { Low-flow } \\
\mathbf{n}=27\end{array}$ & $P$-value \\
\hline Age & $38 \pm 11$ & $35 \pm 8$ & 0.484 \\
Gender $(\mathrm{M} / \mathrm{F})$ & $8 / 9$ & $6 / 21$ & 0.089 \\
Height & $166 \pm 8$ & $164 \pm 9$ & 0.438 \\
Weight & $134 \pm 19$ & $126 \pm 20$ & 0.154 \\
Body mass index & $47 \pm 6$ & $46 \pm 5$ & 0.856 \\
Operation time & $122 \pm 45$ & $144 \pm 51$ & 0.100 \\
Extubation time & $6.2 \pm 3.2$ & $5.5 \pm 2.8$ & 0.352 \\
Recovery time & $10.8 \pm 3.5$ & $8.4 \pm 3.2$ & 0.076 \\
Hemoglobin $(\mathrm{g} / \mathrm{dl})$ & $16.8 \pm 1.7$ & $16.6 \pm 1.4$ & 0.745 \\
\hline
\end{tabular}

Table 2 - Analysis of vital signs.

\begin{tabular}{|c|c|c|c|c|c|c|}
\hline Vital signs & Beginning & $10^{\text {th }} \min$ & $30^{\text {th }} \min$ & $60^{\text {th }} \min$ & Extubation & Postoperative \\
\hline \multicolumn{7}{|l|}{$H R$ (beat/min) } \\
\hline High-flow & $94 \pm 13$ & $96 \pm 11$ & $89 \pm 13$ & $84 \pm 12$ & $78 \pm 19$ & $84 \pm 15$ \\
\hline Low-flow & $91 \pm 17$ & $86 \pm 15$ & $80 \pm 15$ & $84 \pm 15$ & $82 \pm 14$ & $79 \pm 13$ \\
\hline$P$-value & 0.366 & 0.035 & 0.074 & 0.772 & 0.499 & 0.188 \\
\hline \multicolumn{7}{|l|}{$S A P(m m H g)$} \\
\hline High-flow & $156 \pm 21$ & $136 \pm 51$ & $117 \pm 17$ & $124 \pm 25$ & $141 \pm 36$ & $139 \pm 26$ \\
\hline Low-flow & $142 \pm 21$ & $125 \pm 30$ & $114 \pm 23$ & $119 \pm 20$ & $129 \pm 21$ & $130 \pm 19$ \\
\hline P-value & 0.089 & 0.419 & 0.772 & 0.426 & 0.242 & 0.098 \\
\hline \multicolumn{7}{|l|}{$D A P(m m H g)$} \\
\hline High-flow & $94 \pm 18$ & $73 \pm 17$ & $68 \pm 15$ & $80 \pm 23$ & $81 \pm 21$ & $81 \pm 20$ \\
\hline Low-flow & $85 \pm 17$ & $74 \pm 21$ & $68 \pm 18$ & $74 \pm 14$ & $78 \pm 17$ & $76 \pm 17$ \\
\hline $\mathrm{P}$-value & 0.151 & 0.781 & 0.894 & 0.267 & 0.587 & 0.267 \\
\hline \multicolumn{7}{|l|}{$M A P(m m H g)$} \\
\hline High-flow & $117 \pm 19$ & $92 \pm 18$ & $86 \pm 13$ & $93 \pm 17$ & $99 \pm 24$ & $102 \pm 20$ \\
\hline Low-flow & $110 \pm 16$ & $92 \pm 3$ & $85 \pm 20$ & $92 \pm 16$ & $98 \pm 18$ & $98 \pm 16$ \\
\hline P-value & 0.252 & & 0.990 & 0.655 & 0.952 & 0.347 \\
\hline \multicolumn{7}{|l|}{ SPO2 (\%) } \\
\hline High-flow & $95 \pm 3$ & $97 \pm 3$ & $98 \pm 2$ & $96 \pm 4$ & $94 \pm 3$ & $96 \pm 5$ \\
\hline Low-flow & $95 \pm 4$ & $97 \pm 4$ & $98 \pm 2$ & $98 \pm 2$ & $95 \pm 3$ & $97 \pm 3$ \\
\hline P-value & 0.496 & 0.835 & 0.639 & 0.669 & 0.133 & 0.370 \\
\hline \multicolumn{7}{|l|}{$\mathrm{EtCO} 2(\mathrm{~mm} \mathrm{Hg})$} \\
\hline High-flow & $36 \pm 7$ & $34 \pm 4$ & $34 \pm 3$ & $38 \pm 4$ & $36 \pm 4$ & $36 \pm 5$ \\
\hline Low-flow & $35 \pm 7$ & $34 \pm 4$ & $37 \pm 5$ & $38 \pm 5$ & $35 \pm 2$ & $37 \pm 5$ \\
\hline P-value & 0.838 & 0.904 & 0.173 & 0.913 & 0.405 & 0.673 \\
\hline
\end{tabular}

$\mathrm{SpO}_{2}$ : peripheral oxygen saturation, HR: heart rate, SAP: full meaning, MAP: full meaning, EtCO2: end-tidal carbon dioxide 
were evaluated throughout the operation. Patients with low-flow and high-flow anesthesia had similar pressure of oxygen $\left(\mathrm{pO}_{2}\right)$, partial pressure of carbon dioxide $\left(\mathrm{pCO}_{2}\right)$, arterial oxygen saturation $\left(\mathrm{SatO}_{2}\right)$, bicarbonate (HCO3), base excess (BE), and lactate levels ( $p>0.05$ for all) (Table 3). During the entire procedure, including the onset, the 30th, 60th, and 90th minutes, and the extubation period, the patients with low-flow anesthesia showed similar values to those with high-flow anesthesia ( $p>0.05$ for all). Although, the duration of exubation and recovery was shorter in the low-flow anesthesia, albeit not statistically significant.

Discussion. Low-flow anesthesia is becoming increasingly common with the provision of technical infrastructure and the development of continuous and detailed monitoring systems. However, low-flow anesthesia has not been preferred in morbid obese individuals because of the expectation of hypoxia and tissue hypoxia due to the weight of morbidly obese patients. Basic elements of tissue hypoxia include the amount of oxygen presented $\left(\mathrm{fO}_{2}\right)$, which is the amount of blood volume together with cardiac output, and the hemoglobin level. ${ }^{7}$ When tissue oxygenation is calculated in low-flow anesthesia, tissue hypoxia is not expected in healthy obese individuals whose surgical bleeding is replaced. Lactate level is an important indicator that reacts later than $\mathrm{SatO}_{2}$ and $\mathrm{PO}_{2}$ to tissue hypoxia. Here, we found no statistically significant difference in terms of lactate levels. These findings show that adequate tissue oxygenation can be provided at low-flow in obese individuals. However, close monitoring of oxygenation is still required. Low-flow anesthesia has been used in many different patient groups and has been found to be similar to or better than high-flow anesthesia in many ways. $^{12,13}$

Table 3 - Arterial blood gas analysis.

\begin{tabular}{|c|c|c|c|c|c|}
\hline Arterial blood gas analysis & Beginning & $10^{\text {th }} \min$ & $30^{\text {th }} \min$ & $60^{\text {th }} \min$ & Extubation \\
\hline \multicolumn{6}{|l|}{$\mathrm{PO}_{2}(\mathrm{~mm} \mathrm{Hg})$} \\
\hline High-flow & $98 \pm 18$ & $100 \pm 20$ & $103 \pm 13$ & $110 \pm 9$ & $104 \pm 34$ \\
\hline Low-flow & $94 \pm 25$ & $101 \pm 20$ & $102 \pm 19$ & $112 \pm 14$ & $101 \pm 25$ \\
\hline$P$-value & 0.440 & 0.914 & 0.563 & 0.942 & 0.933 \\
\hline \multicolumn{6}{|l|}{$\mathrm{PCO}_{2}(\mathrm{~mm} \mathrm{Hg})$} \\
\hline High-flow & $35 \pm 4$ & $39 \pm 4$ & $40 \pm 4$ & $41 \pm 3$ & $43 \pm 6$ \\
\hline Low-flow & $36 \pm 5$ & $36 \pm 5$ & $39 \pm 5$ & $41 \pm 3$ & $40 \pm 5$ \\
\hline$P$-value & 0.716 & 0.039 & 0.252 & 0.923 & 0.064 \\
\hline \multicolumn{6}{|l|}{$\mathrm{SaO}_{2}(\%)$} \\
\hline High-flow & $98 \pm 3$ & $96 \pm 3$ & $96 \pm 4$ & $97 \pm 1$ & $96 \pm 4$ \\
\hline Low-flow & $97 \pm 3$ & $95 \pm 4$ & $96 \pm 3$ & $97 \pm 2$ & $96 \pm 2$ \\
\hline$P$-value & 0.344 & 0.715 & 0.875 & 0.725 & 0.961 \\
\hline \multicolumn{6}{|l|}{$\mathrm{HCO}_{3}(\mathrm{mmol} / \mathrm{L})$} \\
\hline High-flow & $23.7 \pm 1.2$ & $20.7 \pm 1.5$ & $20.4 \pm 1.9$ & $20.1 \pm 1.0$ & $20.1 \pm 1.1$ \\
\hline Low-flow & $20.7 \pm 1.6$ & $20.5 \pm 2.7$ & $20.3 \pm 1.9$ & $20.3 \pm 1.6$ & $21.0 \pm 1.8$ \\
\hline$P$-value & 0.328 & 0.962 & 0.971 & 0.718 & 0.106 \\
\hline \multicolumn{6}{|l|}{$B E$ (mmol/l) (base excess) } \\
\hline High-flow & $2.3 \pm 1.4$ & $3.9 \pm 1.7$ & $5.1 \pm 1.3$ & $5.0 \pm 1.2$ & $4.9 \pm 1.5$ \\
\hline Low-flow & $2.2 \pm 1.6$ & $3.9 \pm 2.1$ & $4.6 \pm 2.0$ & $4.7 \pm 1.7$ & $4.3 \pm 2.1$ \\
\hline$P$-value & 0.563 & 0.923 & 0.455 & 0.214 & 0.341 \\
\hline \multicolumn{6}{|l|}{$P H$} \\
\hline High-flow & $7.39 \pm 0.05$ & $7.36 \pm 0.06$ & $7.34 \pm 0.06$ & $7.32 \pm 0.05$ & $4.9 \pm 1.5$ \\
\hline Low-flow & $7.39 \pm 0.06$ & $7.36 \pm 0.07$ & $7.36 \pm 0.06$ & $7.31 \pm 0.06$ & $4.3 \pm 2.1$ \\
\hline$P$-value & 0.990 & 0.971 & 0.524 & 0.731 & 0.138 \\
\hline \multicolumn{6}{|l|}{ Lactate (mmol/L) } \\
\hline High-flow & $0.7 \pm 0.3$ & $0.9 \pm 0.4$ & $1.1 \pm 0.6$ & $1.3 \pm 0.8$ & $1.0 \pm 0.3$ \\
\hline Low-flow & $0.7 \pm 0.3$ & $0.9 \pm 0.4$ & $1.3 \pm 0.6$ & $1.4 \pm 0.8$ & $1.0 \pm 0.3$ \\
\hline$P$-value & 0.971 & 0.990 & 0.317 & 0.857 & 0.971 \\
\hline
\end{tabular}


Obesity surgery has the potential to increase the risks of hypoperfusion, bleeding, hypovolemia, and prolonged surgical procedures. Moreover, pulmonary function is limited in morbid obesity. ${ }^{14,15}$ In laparoscopic surgery, a perioperative significant increase of intraabdominal pressure with $\mathrm{CO}_{2}$ infusion is associated with further decrease of lung volumes and decreased diaphragm movements, which is clinically reflected in terms of hypoxia and increased EtCO levels. ${ }^{16-18}$ These patients benefit from intraoperative positive endexpiratory pressure (PEEP) and postoperative breathing exercises. ${ }^{18,19}$ We applied $10 \mathrm{cmH}_{2} \mathrm{O}$ PEEP to prevent atelectasis during the operation. Also, all patients had respiratory exercises during the postoperative period. In the current study, $\mathrm{PCO}_{2}, \mathrm{EtCO}_{2}$, and $\mathrm{SatO}_{2}$ parameters were not different between obese patients receiving high-flow and low-flow anesthesia. We found that the risk for low-flow peripheral perfusion impairment was similar between groups. However, it should be kept in mind that close follow-up is required.

The depth of anesthesia is one of the main concerns of the anesthesiologist during operations. To evaluate the depth of anesthesia, many hemodynamic parameters, such as electroencephalography (EEG), pupil diameter, hemodynamic parameters have been used. Electroencephalography could not be performed because there was no EEG device in our hospital. Also, it was excluded from the evaluation as the pupil diameter may vary due to the narcotics used. Another factor affecting the depth of anesthesia is the use of different agents. ${ }^{20-22}$ In our study, the use of sevoflurane, rocuronium, and fentanyl in all patients neutralized this effect. Also, systolic blood pressure, diastolic blood pressure, mean arterial pressure, and HR were evaluated to assess the depth of anesthesia. These hemodynamic parameters did not differ between the low-flow and high-flow anesthesia groups.

As an important postoperative parameter, recovery time may depend on many variables, including the pharmacodynamics and pharmacokinetics of the anesthetic agent used, the anesthesia technique, operation time, and operation type. ${ }^{23,24}$ Many studies have shown that low-flow anesthesia is similar to or better than high-flow anesthesia in terms of recovery times. ${ }^{10,25}$ In the present study, rescue times were similar in both groups, consistent with the findings of other studies.

Study limitations. Kars is one of the smaller cities in Turkey with a population of approximately 250,000 people. Therefore, the number of patients included in the sample could not be increased during the research process due to such small population and the sociocultural structure; most of our patients came from other cities. Also, since there is no EEG or bispectral index device in our hospital, evaluation of depth of anesthesia was limited.

In conclusion, effects of low-flow anesthesia on arterial blood gas, hemodynamic parameters, and anesthesia recovery times were similar to high-flow anesthesia in laparoscopic obesity surgery. The use of low-flow anesthesia in laparoscopic obesity surgery seems to be safer than high-flow anesthesia in terms of the adequacy of tissue perfusion, depth of anesthesia, and postoperative recovery. We think that with careful monitoring, low-flow anesthesia can be used in obese individuals. However, further research on the matter is still needed.

Acknowledgment. We would like to thank protranslate and for English language editing.https://www.protranslate.net/tr/

\section{References}

1. Doger C, Kahveci K, Ornek D, But A, Aksoy M, Gokcinar D, Katar D. Effects of low-flow sevoflurane anesthesia on pulmonary functions in patients undergoing laparoscopic abdominal surgery. Biomed Res Int 2016; 2016: 3068467.

2. Upadya M, Saneesh PJ. Low-flow anaesthesia - underused mode towards "sustainable anaesthesia". Indian J Anaesth 2018; 62: 166-172.

3. Cui Y, Wang Y, Cao R, Li G, Deng L, Li J. The low fresh gas flow anesthesia and hypothermia in neonates undergoing digestive surgeries: a retrospective before-after study. BMC Anesthesiol 2020; 20: 223.

4. Masa JD, Pépin JL,Borel JC, Mokhlesi B, PB, Sánchez-Quiroga MA. Obesity hypoventilation syndrome. Eur Respir Rev 2019; 28: 180097.

5. Writing Committee for the PROBESE Collaborative Group of the PROtective VEntilation Network (PROVEnet) for the Clinical Trial Network of the European Society of Anaesthesiology, Bluth T, Serpa Neto A, Schultz MJ, Pelosi P, Gama de Abreu M et all. Effect of Intraoperative High Positive End-Expiratory Pressure (PEEP) With Recruitment Maneuvers vs Low PEEP on Postoperative Pulmonary Complications in Obese Patients: A Randomized Clinical Trial. JAMA 2019; 321: 2292-2305.

6. Riad W, Ansari T, Shetty N. Does neck circumference help to predict difficult intubation in obstetric patients? A prospective observational study. Saudi J Anaesth 2018; 12: 77-81.

7. Tezcan B, Erdoğan NM, Erdemli Ö. The solution of the transfusion dilemma: Tissue oxygenation and critical hemoglobin. Acrbadem University Health Science Journal 2015; (1): 7-12.

8. Toker MK, Altıparmak B, Uysal Aİ, Demirbilek SG. [Comparison of pressure-controlled volume-guaranteed ventilation and volume-controlled ventilation in obese patients during gynecologic laparoscopic surgery in the Trendelenburg position]. Rev Bras Anestesiol 2019; 69: 553-560. Portuguese. 
9. Saxena D, Singh P, Dixit A, Arya B, Bhandari M, Sanwatsarkar $S$. Single minute of positive end-expiratory pressure at the time of induction: Effect on arterial blood gases and hemodynamics in morbidly obese patients undergoing laparoscopic bariatric surgery. Anesth Essays Res 2017; 11: 758-761.

10. Akbaş S, Özkan AS. Randomized controlled trial. Comparison of effects of low-flow and normal-flow anesthesia on cerebral oxygenation and bispectral index in morbidly obese patients undergoing laparoscopic sleeve gastrectomy: a prospective, randomized clinical trial. Videosurgery Miniinv 2019; 14: 19-26.

11. Fulton R, Millar JE, Merza M, Johnston H, Corley A, Faulke D, et al. High flow nasal oxygen after bariatric surgery (OXYBAR), prophylactic post-operative high flow nasal oxygen versus conventional oxygen therapy in obese patients undergoing bariatric surgery: study protocol for a randomised controlled pilot trial. Trials 2018; 19: 402.

12. Duymaz G, Yağar S, Özgök A. Comparison of effects of low-flow sevoflurane and low-flow desflurane anaesthesia on renal functions using cystatin C. Turk J Anaesthesiol Reanim 2017; 45: 93-97.

13. Carter LA, Oyewole M, Bates E, Sherratt K. Promoting low-flow anaesthesia and volatile anaesthetic agent choice. $B M J$ Open Qual 2019; 8: e000479.

14. Dixon AE, Peters U. The effect of obesity on lung function. Expert Rev Respir Med 2018; 12: 755-767.

15. Forno E, Han YY, Mullen J, Celedón JC. Overweight, obesity, and lung function in children and adults-a meta-analysis. $J$ Allergy Clin Immunol Pract 2018; 6: 570-581.e10.

16. Akbas S, Ozkan AS. Comparison of effects of low-flow and normal-flow anesthesia on cerebral oxygenation and bispectral index in morbidly obese patients undergoing laparoscopic sleeve gastrectomy: a prospective, randomized clinical trial. Wideochir Inne Tech Maloinwazyjne 2019; 14: 19-26.

17. Tassoudis V, Ieropoulos H, Karanikolas M, Vretzakis G, Bouzia A, Mantoudis E, Petsiti A. Bronchospasm in obese patients undergoing elective laparoscopic surgery under general anesthesia. Springerplus 2016; 5: 435.
18. Alaparthi GK, Augustine AJ, Anand R, Mahale A. Comparison of diaphragmatic breathing exercise, volume and flow incentive spirometry, on diaphragm excursion and pulmonary function in patients undergoing laparoscopic surgery: A randomized controlled trial. Minim Invasive Surg 2016; 2016 : 1967532.

19. Güldner A, Kiss T, Serpa Neto A, Hemmes SN, Canet J, Spieth $\mathrm{PM}$, et al. Intraoperative protective mechanical ventilation for prevention of postoperative pulmonary complications: a comprehensive review of the role of tidal volume, positive end-expiratory pressure, and lung recruitment maneuvers. Anesthesiology 2015; 123: 692-713.

20. Hasan MS, Tan JK, Chan CYW, Kwan MK, Karim FSA, Goh KJ. Comparison between effect of desflurane/remifentanil and propofol/remifentanil anesthesia on somatosensory evoked potential monitoring during scoliosis surgery-A randomized controlled trial. J Orthop Surg (Hong Kong) 2018; 26: 2309499018789529.

21. Williams DC, Brosnan RJ, Fletcher DJ, Aleman M, Holliday TA, Tharp B, et al. Qualitative and quantitative characteristics of the electroencephalogram in normal horses during administration of inhaled anesthesia. J Vet Intern Med 2016; 30: 289-303.

22. Ahmad T, Sheikh NA, Akhter N, Dar BA, Ahmad R. Intraoperative awareness and recall: A comparative study of dexmedetomidine and propofol in cardiac surgery. Cureus 2017; 9: e1542.

23. Dwivedi MB, Puri A, Dwivedi S, Deol H. Role of opioids as coinduction agent with propofol and their effect on apnea time, recovery time, and sedation score. Int J Crit Illn Inj Sci 2018; 8: 4-8.

24. Lai HC, Chan SM, Lu CH, Wong CS, Cherng CH, Wu ZF. Planning for operating room efficiency and faster anesthesia wake-up time in open major upper abdominal surgery. Medicine (Baltimore) 2017; 96: e6148.

25. Chatrath V, Khetarpal R, Bansal D, Kaur H. Sevoflurane in low-flow anesthesia using "equilibration point". Anesth Essays Res 2016; 10: 284-290. 